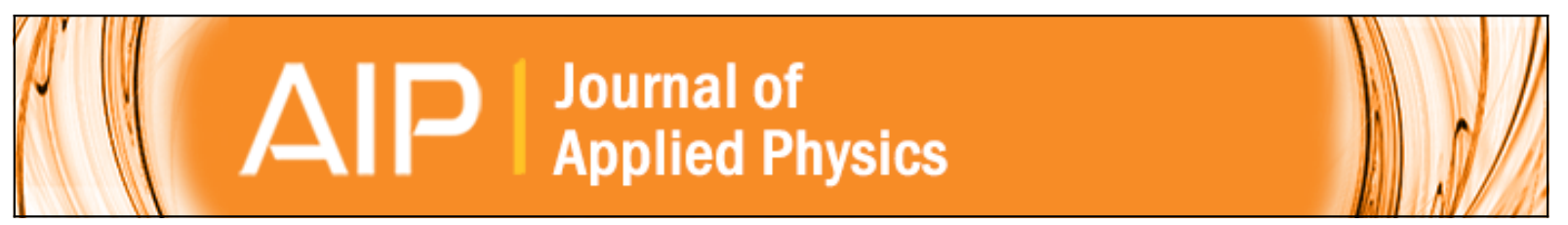

\title{
Synthesis of graphene and graphene nanostructures by ion implantation and pulsed laser annealing
}

Xiaotie Wang, Kara Berke, Nicholas G. Rudawski, Dinesh K. Venkatachalam, Robert G. Elliman, Joel Fridmann, Arthur F. Hebard, Fan Ren, Brent P. Gila, and Bill R. Appleton

Citation: Journal of Applied Physics 120, 025105 (2016); doi: 10.1063/1.4955137

View online: http://dx.doi.org/10.1063/1.4955137

View Table of Contents: http://scitation.aip.org/content/aip/journal/jap/120/2?ver=pdfcov

Published by the AIP Publishing

\section{Articles you may be interested in}

Multienergy gold ion implantation for enhancing the field electron emission characteristics of heterogranular structured diamond films grown on Au-coated Si substrates

Appl. Phys. Lett. 109, 101603 (2016); 10.1063/1.4962537

Low-temperature, site selective graphitization of $\mathrm{SiC}$ via ion implantation and pulsed laser annealing Appl. Phys. Lett. 100, 193105 (2012); 10.1063/1.4707383

Synthesis and laser annealing of embedded CdSe-nanoparticles in Si O 2 by pulsed excimer laser radiation Appl. Phys. Lett. 88, 203123 (2006); 10.1063/1.2205721

Electrical activation of the ion-implanted phosphorus in $4 \mathrm{H}-\mathrm{SiC}$ by excimer laser annealing

J. Appl. Phys. 93, 5934 (2003); 10.1063/1.1565190

Free electron laser annealing of $\mathrm{N}$-ion-implanted $3 \mathrm{C}$-SiC films

Appl. Phys. Lett. 71, 823 (1997); 10.1063/1.119668

\section{High Energy Nanosecond Lasers}

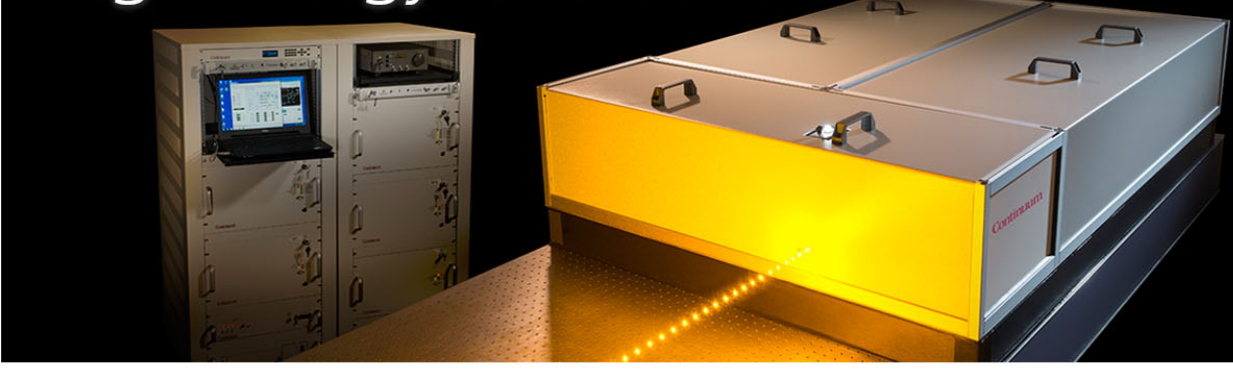




\title{
Synthesis of graphene and graphene nanostructures by ion implantation and pulsed laser annealing
}

\author{
Xiaotie Wang, ${ }^{1}$ Kara Berke, ${ }^{2}$ Nicholas G. Rudawski, ${ }^{1}$ Dinesh K. Venkatachalam, ${ }^{3}$ \\ Robert G. Elliman, ${ }^{3}$ Joel Fridmann, ${ }^{4,5}$ Arthur F. Hebard, ${ }^{2}$ Fan Ren, ${ }^{6}$ Brent P. Gila, ${ }^{1,4}$ \\ and Bill R. Appleton ${ }^{1}$ \\ ${ }^{1}$ Department of Materials Science and Engineering, University of Florida, Gainesville, Florida 32611, USA \\ ${ }^{2}$ Department of Physics, University of Florida, Gainesville, Florida 3261, USA \\ ${ }^{3}$ Department of Electronic Materials Engineering, Australian National University, Canberra, \\ Australian Capital Territory 0200, Australia \\ ${ }^{4}$ Nanoscience Institute for Medical and Engineering Technology, University of Florida, Gainesville, \\ Florida 32601, USA \\ ${ }^{5}$ Raith USA, Incorporated, Ronkonkoma, New York 11779, USA \\ ${ }^{6}$ Department of Chemical Engineering, University of Florida, Gainesville, Florida 3261, USA
}

(Received 24 March 2016; accepted 21 June 2016; published online 12 July 2016)

\begin{abstract}
In this paper, we report a systematic study that shows how the numerous processing parameters associated with ion implantation (II) and pulsed laser annealing (PLA) can be manipulated to control the quantity and quality of graphene (G), few-layer graphene (FLG), and other carbon nanostructures selectively synthesized in crystalline $\mathrm{SiC}(\mathrm{c}-\mathrm{SiC})$. Controlled implantations of $\mathrm{Si}^{-}$plus $\mathrm{C}^{-}$and $\mathrm{Au}^{+}$ ions in $\mathrm{c}-\mathrm{SiC}$ showed that both the thickness of the amorphous layer formed by ion damage and the doping effect of the implanted Au enhance the formation of G and FLG during PLA. The relative contributions of the amorphous and doping effects were studied separately, and thermal simulation calculations were used to estimate surface temperatures and to help understand the phase changes occurring during PLA. In addition to the amorphous layer thickness and catalytic doping effects, other enhancement effects were found to depend on other ion species, the annealing environment, PLA fluence and number of pulses, and even laser frequency. Optimum II and PLA conditions are identified and possible mechanisms for selective synthesis of G, FLG, and carbon nanostructures are discussed. Published by AIP Publishing. [http://dx.doi.org/10.1063/1.4955137]
\end{abstract}

\section{INTRODUCTION}

In previous experiments, we demonstrated that ion implantation (II) and pulsed laser annealing (PLA) could be applied to selectively synthesize graphene $(\mathrm{G})$ and few-layer graphene (FLG) on crystalline silicon carbide (c-SiC), only where ions were implanted, with nanoscale precision and control, and without altering the surrounding or underlying c-SiC. ${ }^{1,2}$ The motivation for these initial experiments was to develop a processing approach using multi-ion beam lithography ${ }^{3}$ combined with thermal or PLA to write nanoscale $G$ features directly onto insulating $\mathrm{c}-\mathrm{SiC}$ in a manner that avoided using many of the conventional lithographic processing techniques (chemical etching, laydown/liftoff, transfer, etc.). Since II and PLA are processing approaches widely used in current device manufacturing, we considered this a promising approach for some $G$ nanoscale device and sensor applications.

While this processing approach was shown to be quite successful, it left a number of unresolved questions concerning the exact mechanisms controlling the synthesis of the $\mathrm{G}$ and FLG. Additional experiments since have shown that the origins of these ambiguities are closely allied with the advantageous strengths of the II and PLA processing techniques. Namely, II and PLA are inherently non-equilibrium processing techniques (ion damage, doping, cascade quenching, etc.; laser rapid heating/melting, resolidification, etc.); each has multiple processing control features (implanted ion species, dose/dose-rate, energy/depth-profiles, laser fluence, pulse duration, number of pulses, etc.); and the processing environment also affects results.

In this paper, we report on controlled experiments that explore how the multiple II and PLA processing parameters can be combined and controlled to selectively synthesize graphene nano-structures; identify how these parameters can be optimized to achieve desired results; and discuss the mechanisms responsible for synthesis of G, FLG, and other graphene nano-structures.

\section{EXPERIMENTAL METHODS}

Single crystalline $4 \mathrm{H}$ and $6 \mathrm{H} \mathrm{SiC}$ wafers were purchased from II-VI, Inc. Nanoscale patterning of graphene features utilized a multi-ion beam lithography, nanofabrication, and engineering (MionLiNE) system at the University of Florida (UF). ${ }^{3}$ For some experiments, it was desirable to do a variety of experiments on a single $\mathrm{SiC}$ sample to eliminate potential sample differences, and in these cases, broad area implantations were done at the Australian National University (ANU).

Pulsed laser annealing was performed at UF with a $193 \mathrm{~nm}$ wavelength, $25 \mathrm{~ns}$ pulse-width JPSA IX-260 ArF laser. The laser has a double fly's eye beam homogenizer system to produce spatially uniform irradiations. A mask system can control laser exposure areas such as $25 \mu \mathrm{m} \times 25 \mu \mathrm{m}$, and a precision $\mathrm{X}-\mathrm{Y}$ positioning table and microscope system can 
be programmed to position exposure areas with a resolution of $\pm 1 \mu \mathrm{m}$ and stage movement repeatability of $\pm 0.1 \mu \mathrm{m}$. Laser fluence, number of pulses, and frequency can be varied over a wide range.

Sample analyses included Raman spectra using a Horiba MicroRaman Spectrometer with a $532 \mathrm{~nm}$ green laser, Auger electron spectroscopy (AES), X-ray diffraction, scanning electron microscopy (SEM), thermal simulation calculations, and ion scattering/channeling performed at ANU. Complementary high-resolution cross-sectional transmission electron microscopy (HR-XTEM) was performed at UF to directly image the near-surface regions of the SiC wafers using a JEOL 2010F transmission electron microscope operated at $200 \mathrm{kV}$. Samples were prepared using an FEI DB235 dual scanning electron microscope/focused ion beam (FIB) system with methods described elsewhere. ${ }^{4-7}$ Prior to performing FIB cross-section milling, the specimens were coated with $\sim 100 \mathrm{~nm}$ of $\mathrm{Cr}$, and occasionally $\mathrm{Pt}$, to protect the surface of the specimens; ${ }^{8}$ this Cr layer was not present during PLA.

\section{RESULTS AND DISCUSSION}

While our initial experiments ${ }^{1,2}$ successfully demonstrated that II and PLA could be combined to selectively synthesized $\mathrm{G}$ and FLG on $\mathrm{SiC}$, and with nanoscale precision, the results raised a number of questions concerning the contributing mechanisms and the optimum processing parameters. For example, laser fluences of $1.0-1.2 \mathrm{~J} / \mathrm{cm}^{2}$ were required to initiate graphitization of unimplanted $\mathrm{c}-\mathrm{SiC}$. But when other c-SiC samples were implanted with a variety of different ions [Si (self-dopant), Ge (isoelectronic), Au (noble/catalytic), and $\mathrm{Cu}$ (catalytic)], the laser threshold-fluence for the onset of graphitization, $\Phi_{\mathrm{G}}$, varied widely- $\Phi_{\mathrm{G}}(\mathrm{Cu}) \sim 0.1 \mathrm{~J} / \mathrm{cm}^{2}, \Phi_{\mathrm{G}}$ (Au) $\sim 0.3 \mathrm{~J} / \mathrm{cm}^{2}, \Phi_{\mathrm{G}}(\mathrm{Ge}) \sim 0.5 \mathrm{~J} / \mathrm{cm}^{2}$. It is well known that ion implantation doses as low as $\sim 10^{14}-10^{15}$ ions $/ \mathrm{cm}^{2}$ can damage c-SiC and can render the near-surface material to an amorphous state. ${ }^{9}$ Previous research has shown that the threshold for melting the surface of a-SiC is strongly dependent on the thickness of the amorphous $\mathrm{SiC}$ layer. ${ }^{10-12} \mathrm{So}$, it was unclear whether the strong dependence we observed for the $\Phi_{\mathrm{G}}$ threshold on implanted ion species was due to the amorphous surface layer produced by the ion implantation process, or to a catalytic effect due to the implanted ion species (doping), or both. To investigate further, we devised experiments to study these effects separately.

\section{The effects of amorphous SiC surface layers}

Amorphous layers of various thicknesses were produced on the (000-1) (C-face) of 6H-SiC single crystalline wafers by ion implantation of $\mathrm{Si}^{-}$and $\mathrm{C}^{-}$negative ions at projected ranges and fluences to produce stoichiometric distributions. This approach produces a relatively "pure" a-SiC layer. Stopping and Range of Ions in Matter (SRIM) ${ }^{13}$ calculations were used to estimate the ion energies and fluences needed to produce various thickness a-SiC layers, and the experimental conditions are shown in Table I. Ion scattering/channeling measurements were used to measure the resulting amorphous layer thicknesses, and these were confirmed by HR-XTEM as illustrated in Figure 1. The ion implantations
TABLE I. Implantation parameters for forming a-SiC layers on c-SiC.

\begin{tabular}{|c|c|c|c|c|c|}
\hline \multirow{2}{*}{$\begin{array}{l}\text { Sample } \\
\text { number }\end{array}$} & \multicolumn{2}{|r|}{$\mathrm{Si}$} & \multicolumn{2}{|r|}{$\mathrm{C}$} & \multirow{2}{*}{$\begin{array}{l}\text { Amorphous } \\
\text { layer } d_{\alpha}(\mathrm{nm})\end{array}$} \\
\hline & $\mathrm{E}(\mathrm{keV})$ & $\left(10^{15} \mathrm{Si}^{-} / \mathrm{cm}^{2}\right)$ & $\mathrm{E}(\mathrm{keV})$ & $\left(10^{15} \mathrm{C}^{-} / \mathrm{cm}^{2}\right)$ & \\
\hline 1 & 10 & 1.5 & 4 & 1.75 & 20 \\
\hline 2 & 40 & 1.5 & 18 & 1.5 & 69.7 \\
\hline 3 & 60 & 1.5 & 27 & 1.5 & 98.9 \\
\hline 4 & 80 & 1.5 & 37 & 1.5 & 123.8 \\
\hline 5 & 160 & 1.8 & 75 & 1.8 & 216.7 \\
\hline
\end{tabular}

and ion beam analyses were performed at ANU and HR$\mathrm{XTEM}$ at UF. Ion beam analysis was done with $2.0 \mathrm{MeV}$ $\mathrm{He}^{+}$, scattering angle $110^{\circ}$, and $20^{\circ}$ exit angle relative to the surface.

This approach of using stoichiometric implantation produces a uniform a-SiC layer as Figure 1(b) indicates for the $20 \mathrm{~nm}$ thick layer (sample 1). Using samples 1-5, PLA parameters could be optimized over the range of thicknesses from $20-217 \mathrm{~nm}$ for the "pure" amorphous layers and compared to results when dopant atoms are implanted into these
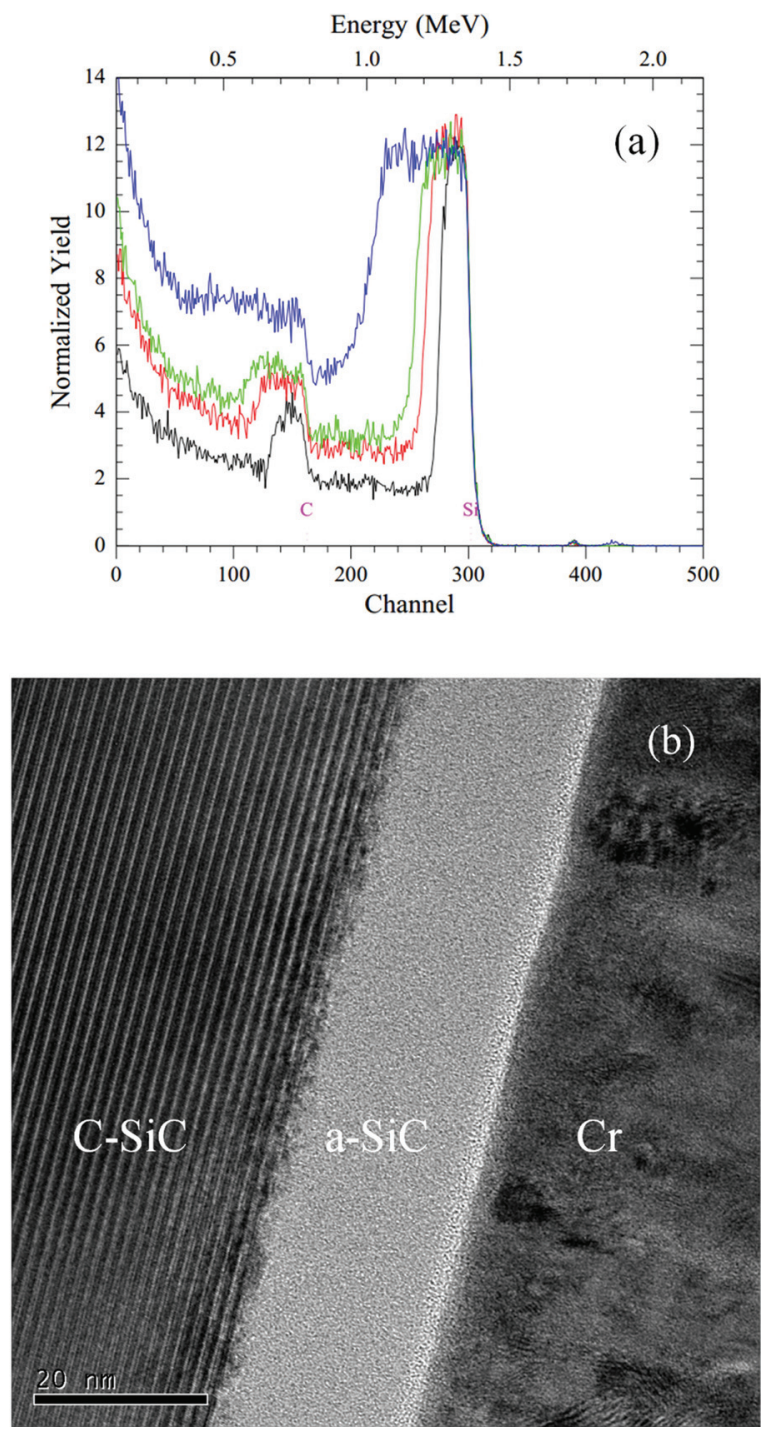

FIG. 1. (a) Representative ion scattering channeling measurements for various thickness a-SiC layers on c-SiC and (b) HR-XTEM of $20 \mathrm{~nm}$ thick a-SiC on c-SiC. 
layers. But, first, it is useful to estimate how amorphous layer thicknesses affect surface temperatures for our laser annealing conditions.

\section{Thermal simulations}

Early studies by Baeri et al. used time-resolved reflectivity experiments to determine the minimum laser fluences required from a pulsed Ruby laser to melt a-SiC layers of different thicknesses, produced by $\mathrm{Ar}^{+}$ion implantation; ${ }^{10}$ and related numerical simulations were conducted by Dutto et al. ${ }^{11}$ and Hedler et al. ${ }^{12}$ We performed similar calculations for our different experimental conditions. A finite element analysis was used to estimate the surface temperature during the PLA process. We used an unsteady-state energy balance equation with rectangular coordinates $(\mathrm{x}-, \mathrm{y}-, \text { and } \mathrm{z} \text {-axes })^{14}$ to approximate the surface temperatures of ion-implanted samples after exposure to one $25 \mathrm{~ns}$ laser pulse as shown by

$$
k\left[\frac{\partial^{2} T}{\partial x^{2}}+\frac{\partial^{2} T}{\partial y^{2}}+\frac{\partial^{2} T}{\partial z^{2}}\right]+\alpha I(z, t)=\rho C_{p} \frac{\partial T}{\partial t},
$$

where $T$ is temperature, $\rho$ is density, $C_{p}$ is heat capacity, $\alpha$ is absorption coefficient, $k$ is thermal conductivity (in units of $\mathrm{W} / \mathrm{cm} \mathrm{K}), z$ is distance from the sample surface, $t$ is time, and $I$ is absorbed power during laser exposure. This can be represented as a function of $z$ and $t$ by using

$$
I(z, t)=I_{0}(t)(1-R) \exp (-\alpha z),
$$

where $I_{0}$ is the incident laser intensity at the sample surface $(z=0)$ and $R$ is the reflectivity of the specimen.

Assuming the $\mathrm{SiC}$ surface melts within the depth of laser's penetration depth $d p$, the heat that is required for $\mathrm{SiC}$ to transform from solid phase to liquid phase could be represented as a function of mass and latent heat of fusion

$$
Q=m L,
$$

where $L$ is the latent heat of fusion and $m$ is the mass of $\mathrm{SiC}$ surface with a depth of laser's penetration depth, $d p=1 / \alpha . \mathrm{m}$ is presented as

$$
m=\rho A d p=\rho A / \alpha,
$$

where $\rho$ is density, $A$ is area, $d p$ is laser's penetration depth, and $\alpha$ is absorption coefficient. Therefore, when $A$ is $1 \mathrm{~cm}^{2}$ and the penetration depth $d p$ is $9.1 \mathrm{~nm}$, this latent heat of fusion $Q$ is $3.14 \times 10^{-3} \mathrm{~J}$, which means it requires a laser fluence of $3.14 \times 10^{-3} \mathrm{~J} / \mathrm{cm}^{2}$ for solid to liquid $\mathrm{SiC}$ phase change.

Figure 2 shows the laser fluence required to melt a given thickness of a-SiC on c-SiC, based on our thermal simulation results. We used $2445 \mathrm{~K}$ as the a-SiC melting temperature, ${ }^{10-12}$ and the remaining thermal properties of a-SiC and $\mathrm{c}-\mathrm{SiC}$ are listed in Table II. The trend of decreasing fluence with increasing thickness is due to the poor thermal conductivity of a-SiC compared to c-SiC. When the laser energy is absorbed in the amorphous layer, the heat is conducted relatively slowly until it reaches the c-SiC substrate where is

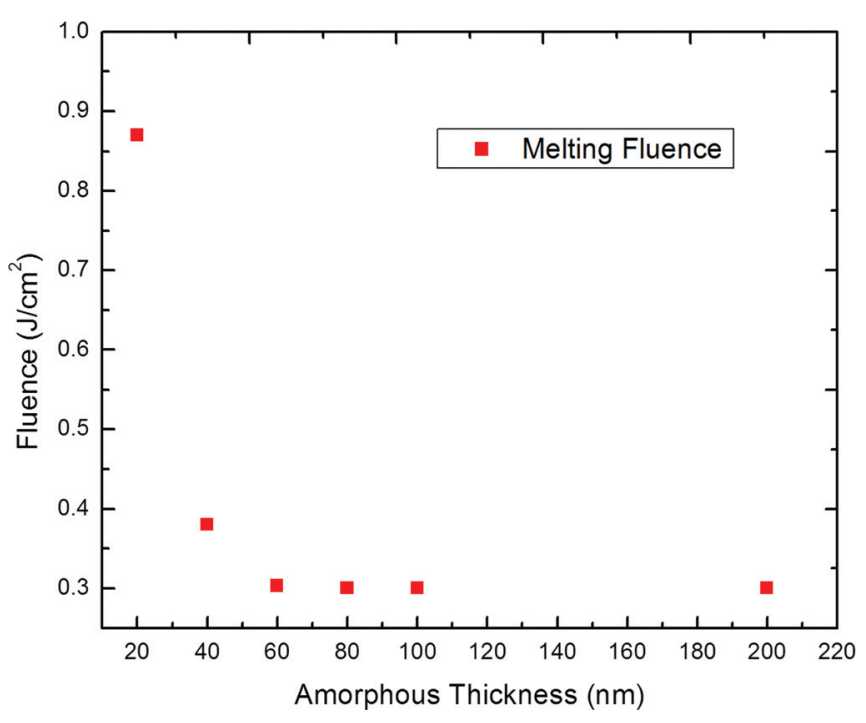

FIG. 2. Thermal simulation results estimating laser fluences required to melt certain thicknesses of amorphous $\mathrm{SiC}$ on $\mathrm{c}-\mathrm{SiC}$. Melting temperature of amorphous $\mathrm{SiC}, \mathrm{T}_{\mathrm{m}}$ is used as $2445 \mathrm{~K}$.

conducted away much more rapidly. Consequently, the thinner the amorphous layer, the more efficiently the heat is conducted away and so higher laser fluences are required to melt thin amorphous layer than thick ones. Based on the latent heat of fusion calculation, the fluence that required for solid to liquid $\mathrm{SiC}$ surface phase change is much smaller than the fluence required to heat the entire sample from room temperature to melting temperature. Therefore, the latent heat of fusion could be negligible during the thermal simulation. It should also be noted that the simulation results are only applicable for the initial pulse. As will be shown, depending on fluence, the first pulse can melt or change the thickness of the amorphous layer; transform it to polycrystalline $\mathrm{SiC}, \mathrm{G}$, or other carbon nanostructures, etc.; and such changes can present different thermal properties for subsequent pulses. However, these calculations still constitute a useful guide for estimating the temperature range during PLA. Fortunately, HR-XTEM can confirm whether the sample surface melts or changes phase.

\section{Raman assessment after PLA a-SiC}

The results of PLA on the various thicknesses of a-SiC layers $\left(d_{\alpha}\right)$ with a variety of laser processing parameters were studied using Raman spectroscopy and HR-XTEM. Figure 3 compares Raman spectra for samples 1-3 and pristine c-SiC. The peaks at $1350 \mathrm{~cm}^{-1}, 1580 \mathrm{~cm}^{-1}$, and $2700 \mathrm{~cm}^{-1}$ are

TABLE II. Parameters for $\mathrm{SiC}$ used in thermal simulation calculations. ${ }^{12}$

\begin{tabular}{lcc}
\hline \hline Parameter & Amorphous SiC & Crystalline $6 \mathrm{H}-\mathrm{SiC}$ \\
\hline Density, $\rho\left(\mathrm{g} / \mathrm{cm}^{3}\right)$ & 2.66 & 3.21 \\
Specific heat, $C_{p}(\mathrm{~J} / \mathrm{g} \mathrm{K})$ & 1.3 & 1.3 \\
Thermal conductivity, $\kappa(\mathrm{W} / \mathrm{cm} \mathrm{K})$ & 0.011 & 4.9 \\
Absorption coefficient, $\alpha\left(10^{6} / \mathrm{cm}\right)$ & 1.1 & 1.5 \\
Reflectivity, $R(\%)$ & 34.6 & 40 \\
Melting point, $T_{m}(\mathrm{~K})$ & 2445 & 3100 \\
Latent heat of fusion, $\mathrm{L}(\mathrm{J} / \mathrm{g})$ & 1300 & $\cdots$ \\
\hline \hline
\end{tabular}




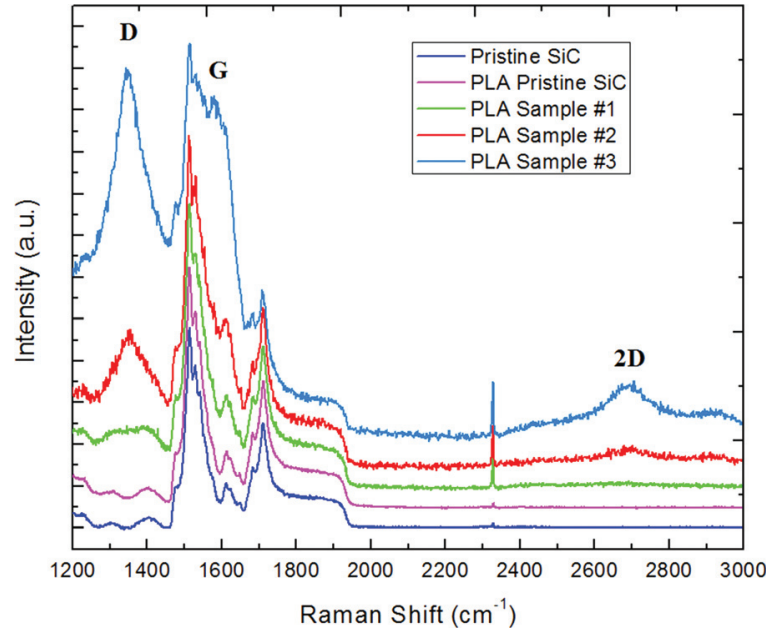

FIG. 3. Raman spectrum for pristine SiC, PLA pristine SiC, sample \#1, sample \#2, and sample \#3.

referred to as $\mathrm{D}, \mathrm{G}$, and $2 \mathrm{D}$ peaks characteristic of graphene, respectively. ${ }^{15}$ In general, the $\mathrm{G}$ peak indicates $\mathrm{sp}^{2}$ bonding (in plane stretching of $\mathrm{C}-\mathrm{C}$ bonds), 2D represents a greater degree of $\mathrm{sp}^{2}$ bonding order (such as $\mathrm{G}, \mathrm{FLG}$, and carbon nanostructures), and the $\mathrm{D}$ peak represents disorder in the system. As $d_{\alpha}$ for samples 1-3 increases, the relative intensities of the D, G, and 2D peaks increase. The trends in the Raman signals due to graphitic carbon can be isolated by normalizing and subtracting the $\mathrm{c}-\mathrm{SiC}$ signal at $1520 \mathrm{~cm}^{-1}$ and comparing the intensity of the graphitic peaks $\left(\mathrm{I}_{\mathrm{G}}, \mathrm{I}_{2 \mathrm{D}}\right.$, $\left.I_{D}\right)$. If this is done, the intensity of each spectrum's D peak $\left(\mathrm{I}_{\mathrm{D}}\right)$ is comparable to the intensity of its $\mathrm{G}$ peak $\left(\mathrm{I}_{\mathrm{G}}\right)$, indicating a significant amount of disorder in all samples. The high degree of disorder also leads to the appearance of the $\mathrm{D}$ peak at $1620 \mathrm{~cm}^{-1}$ and the $\mathrm{D}+\mathrm{G}$ peak at $2930 \mathrm{~cm}^{-1}$.

\section{HR-XTEM assessment after PLA a-SiC}

To evaluate the structural modifications resulting from PLA, HR-XTEM was performed on both c-SiC and the amorphized samples in Table I. Figure 4 compares PLA results for a $6 \mathrm{H} \mathrm{c}$-SiC sample to sample 1 with a $22 \mathrm{~nm}$ thick stoichiometric amorphous surface layer. Both were annealed in 1 atmosphere of Ar with 2000, $25 \mathrm{ns,} 193 \mathrm{~nm}$ pulses, at $0.8 \mathrm{~J} / \mathrm{cm}^{2}$ and $50 \mathrm{~Hz}$. At this fluence, both are below the melt threshold for one pulse. After 2000 pulses, Figure 4(a) shows no evidence of change to the c-SiC surface, but Figure 4(b) shows that the amorphous surface layer has decomposed forming 4-5 G layers on the crystalline substrate and an amorphous layer above containing both $\mathrm{Si}$ and $\mathrm{C}$ atoms. While 2000 pulses at $0.8 \mathrm{~J} / \mathrm{cm}^{2}$ do not alter the $6 \mathrm{H}$ crystal, the rapid heating and cooling reach higher temperatures that are sufficient to free and drive $\mathrm{Si}$ atoms toward the surface, leaving $\mathrm{C}$ atoms behind to bond and form FLG on the c-SiC surface.

Figure 5 shows HR-XTEM results for sample 4 $\left(d_{\alpha}=124 \mathrm{~nm}\right)$ where PLA at 100 pulses at $0.8 \mathrm{~J} / \mathrm{cm}^{2}$ is above the melt threshold. The results in Figure 5(a) are consistent with the interpretation that the amorphous surface layer melts next to the $6 \mathrm{H} \mathrm{c}-\mathrm{SiC}$ substrate, and repeated pulses cause rapid cooling near the crystalline substrate forming polycrystalline 3C-SiC, and an amorphous region above where carbon nanostructures formed. Figure 5(b) shows that FLG formed at the sample surface; 5(c) shows that carbon nano-onions formed in the middle of the amorphous layer; and 5(d) shows the formation of graphitic nanostructures forming in the light regions within the $3 \mathrm{C}$ poly that are trapped amorphous regions.

Carbon nano-and-micro-structures like those we have observed, sometimes referred to as onions because of their shapes, were first observed by Iijima, ${ }^{16}$ after heating carbon black rods to extremely high temperatures $(>4000 \mathrm{~K})$. Other synthesis methods have since been recognized, including high energy electron irradiation of carbon soot, ${ }^{17}$ arc discharge in water from a carbon target, ${ }^{18}$ and carbon ion implantation in $\mathrm{Cu}$ substrates. ${ }^{19}$ All of these methods involve non-equilibrium conditions such as rapid heating of carboncontaining precursors to high temperatures or ion implantation where ion induced damage cascades quench rapidly. The carbon-onions observed in sample 4 most likely form due to the rapid melting and re-solidification of a- or $\mathrm{c}-\mathrm{SiC}$ that occurs during our $25 \mathrm{~ns}$ PLA. In our case, repeated pulses can deplete the amorphous areas of Si leaving excess $\mathrm{C}$ atoms to bond with each other in 3-dimensional space into spherical and multi-shell arrangements. However, the HR-XTEM images indicate that the formation of FLG mainly stabilizes at interfaces such as the sample surface or amorphous/crystalline interfaces, or at the amorphous surface. Therefore, a thinner amorphous layer enhances G and FLG formation and limits the possibility of carbon-onions growth.

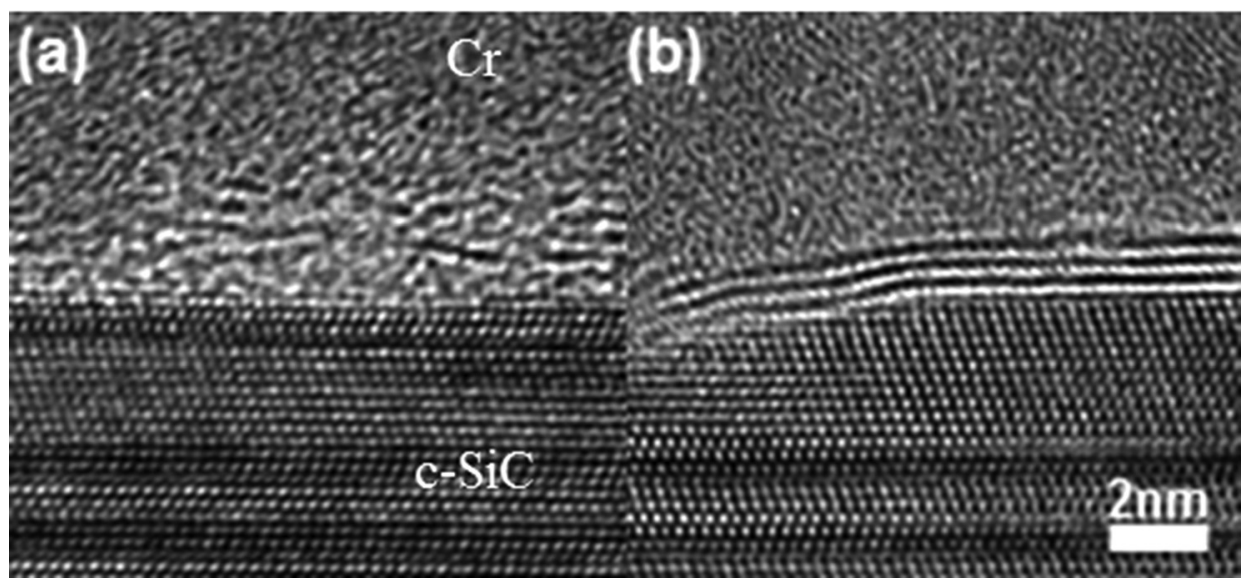

FIG. 4. PLA in 1 atm. Ar with 2000, $25 \mathrm{~ns}, 0.8 \mathrm{~J} / \mathrm{cm}^{2}$, ArF pulses at $50 \mathrm{~Hz}$. (a) $6 \mathrm{H} \mathrm{c}-\mathrm{SiC}$ and (b) c-SiC with a $22 \mathrm{~nm}$ thick stoichiometric II amorphous surface layer $22 \mathrm{~nm}$ thick. (Below the "melt" threshold for both a-or-c-SiC). 


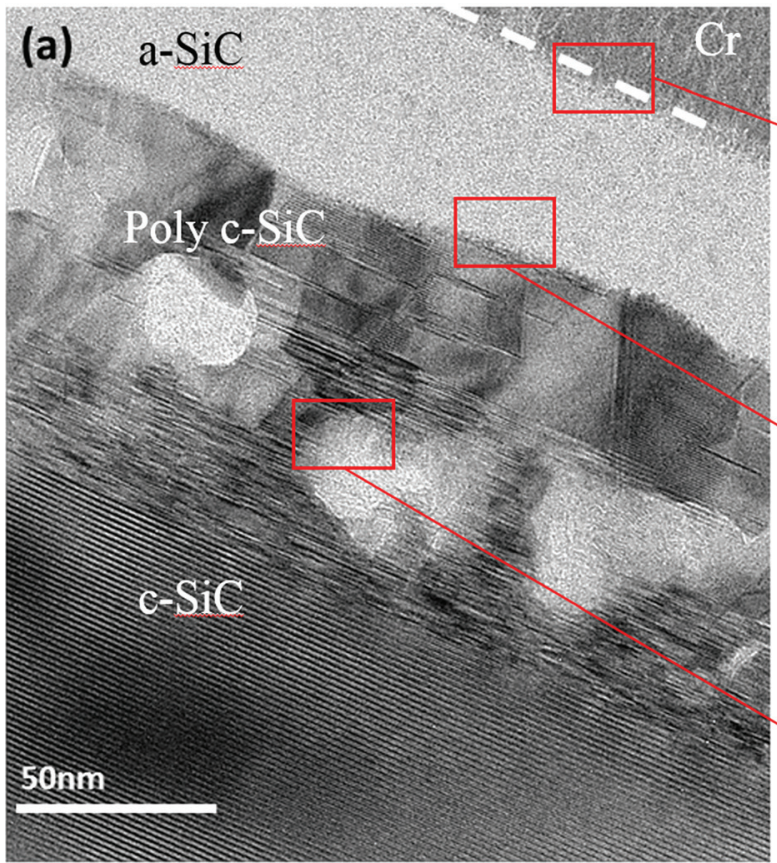

\section{Catalytic or doping effects; Au implantation}

We began these experiments to help differentiate the role of the amorphous surface layers from the ion species used to create the amorphous layers during PLA. The previous results and discussion helped clarify how an amorphous surface layers on c-SiC can affect PLA. Now, we want to see if there is a doping or catalytic effect. In order to isolate any "catalytic effect" of implanted species, two samples were prepared from the same crystal by implanting equal amounts of $\mathrm{Si}^{-}(1.5$ $\times 10^{15}$ ions $\left./ \mathrm{cm}^{2}, 10 \mathrm{keV}\right)$ and $\mathrm{C}^{-}\left(1.5 \times 10^{15} \mathrm{ions} / \mathrm{cm}^{2}\right.$, $4 \mathrm{keV}$ ) into $6 \mathrm{H}-\mathrm{SiC}$ to form $20 \mathrm{~nm}$-thick amorphous $\mathrm{SiC}$ surface layers. The first sample was used as a control, and the second sample was additionally implanted with $\mathrm{Au}^{+}\left(5 \times 10^{15}\right.$ ions $/ \mathrm{cm}^{2}, 30 \mathrm{keV}$ ) into the amorphous region. The thickness of the amorphous layer was measured by ion scattering/channeling at ANU and verified as $20 \mathrm{~nm}$ by HR-XTEM at the University of Florida [see Figure 1(b)]. These two sampleslaser annealed with 2000 pulses at $0.8 \mathrm{~J} / \mathrm{cm}^{2}, 50 \mathrm{~Hz}$ in Argon ambient-are compared in Figure 6. Figure 6(a) shows a TEM image of a-SiC without the $\mathrm{Au}^{+}$implant that has 2-3 layers of $\mathrm{G}$ formed on the crystalline substrate. Figure 6(b) shows a TEM image of a-SiC with the $\mathrm{Au}^{+}$implant that has nine or ten layers of $\mathrm{G}$ formed with uniform coverage.

These results show that Au implantation increases the formation of G layers and confirms that there is a "catalytic" or "doping" effect. When combined with the "amorphous effect," this offers additional control for utilizing II and PLA to selectively form $\mathrm{G}$ on $\mathrm{SiC}$.

\section{Optimizing PLA parameters}

The prior experiments and discussions have shown that applying PLA to selectively synthesize G and G-like structures in $\mathrm{SiC}$ is affected by both the amorphous surface layers produced by II, and by the species of ion used. In this section, the effects of fluence, number of pulses, frequency of pulse delivery, and sample environment during PLA are studied to further identify optimum conditions.

\section{PLA melting effects; high fluences}

To supplement the understanding of the amorphous surface layer and doping effects, PLA of c-SiC was also studied.
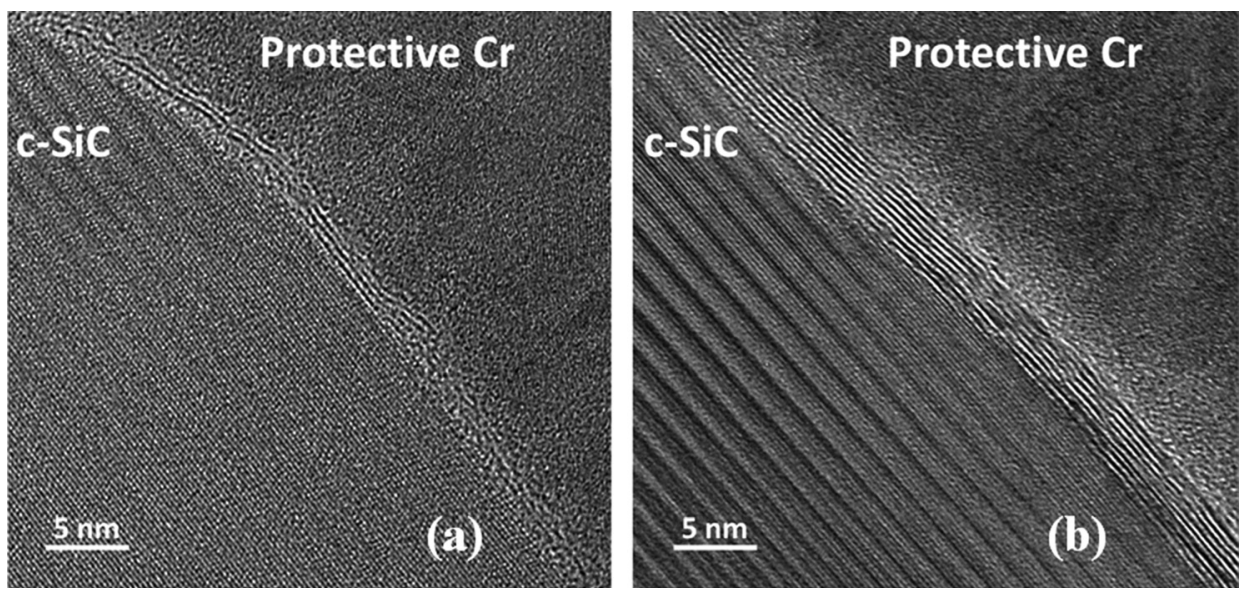

FIG. 6. HR-XTEM images (a) HRXTEM image of pulse laser annealing of amorphous $\mathrm{SiC}$ without $\mathrm{Au}^{+}$implant, with 2000 laser pulses at $800 \mathrm{~mJ} / \mathrm{cm}^{2}$. (b) HR-XTEM image of pulse laser annealing of amorphous $\mathrm{SiC}$ implanted with $\mathrm{Au}^{+}$ions, with 2000 laser pulses at $800 \mathrm{~mJ} / \mathrm{cm}^{2} .100 \mathrm{~nm}$ thick $\mathrm{Cr}$ was sputtered onto sample before FIB and $\mathrm{x}$ TEM imaging for protection purpose during the FIB sample preparation process. 
PLA without II has also been studied by Lee et al., ${ }^{24}$ Hwang et al., ${ }^{25}$ and Hattori et al $^{26}$ using $\mathrm{KrF}$ pulsed lasers $(\sim 1.2 \mathrm{~J} /$ $\mathrm{cm}^{2}, 25 \mathrm{~ns}$ ). To evaluate how melting affected the structure and graphene growth for our conditions, HR-XTEM and Raman were used to study PLA fluences from $0.1-1.0 \mathrm{~J} / \mathrm{cm}^{2}$ at $50 \mathrm{~Hz}$, on $4 \mathrm{H} \mathrm{c}-\mathrm{SiC}$, both above and below $\Phi_{\mathrm{m}}$. Thermal simulations were performed to estimate the surface peak temperature of $\mathrm{c}-\mathrm{SiC}$ from a single pulse at different laser fluences ranging from 0.1 to $1.0 \mathrm{~J} / \mathrm{cm}^{2}$ as shown in Figure 7 . The fluence that melts the surface is defined as $\Phi_{\mathrm{m}}$, and $\Phi_{\mathrm{m}}$ is $\sim 0.905 \mathrm{~J} / \mathrm{cm}^{2}$ for $\mathrm{SiC}$ based on the simulation. Below $\Phi_{\mathrm{m}}$, peak temperature follows a linear relationship with fluence, and the SiC remains in the solid phase. Above $\Phi_{\mathrm{m}}$, the surface reaches the melting temperature, and $\mathrm{c}-\mathrm{SiC}$ at the top surface changes from solid to liquid, the laser light reflection increases, and absorption decreases in the liquid state. However, the practical reflectivity during melting is not easily available and was estimated as shown by the red dashed line.

The HR-XTEM images of the SiC crystal were taken after 1, 10, and 100-pulse and are compared in Figure 8. For clarity, Figures 8(a), 8(c), and 8(e) are intentionally aligned, so the surface is at the same level. In Figure 8(a), 1 laser pulse at $1 \mathrm{~J} / \mathrm{cm}^{2}$ melted the $\mathrm{c}-\mathrm{SiC}$ at the near surface, and recrystallization yields a $\sim 20 \mathrm{~nm}$ thick polycrystalline $3 \mathrm{C}$ $\mathrm{SiC}$ on the $4 \mathrm{H} \mathrm{c}-\mathrm{SiC}$ substrate, and a thin amorphous layer and few layers of graphene on top. Figure 8(b) magnifies the surface area in Figure 8(a) and shows that 2-3 layers of graphene have formed on top of the surface, but the quality is not the best and these FLG samples appear to be discontinuous. The corresponding Raman spectra showed only tiny $G$ and $2 \mathrm{D}$ signals corresponding to $\mathrm{sp}^{2}$ bonding and a strong $\mathrm{SiC}$ signal, indicating that the original crystal structure was still largely intact. Figure $8(\mathrm{c})$ is the TEM image after 10 laser annealing pulses at $1 \mathrm{~J} / \mathrm{cm}^{2}$. Apparently, the amorphous layer increases to around $60 \mathrm{~nm}$, and the polycrystalline $3 \mathrm{C}$ $\mathrm{SiC}$ seems still around $20 \mathrm{~nm}$ but much more non-uniform. The magnified TEM image in Figure 8(d) shows that many

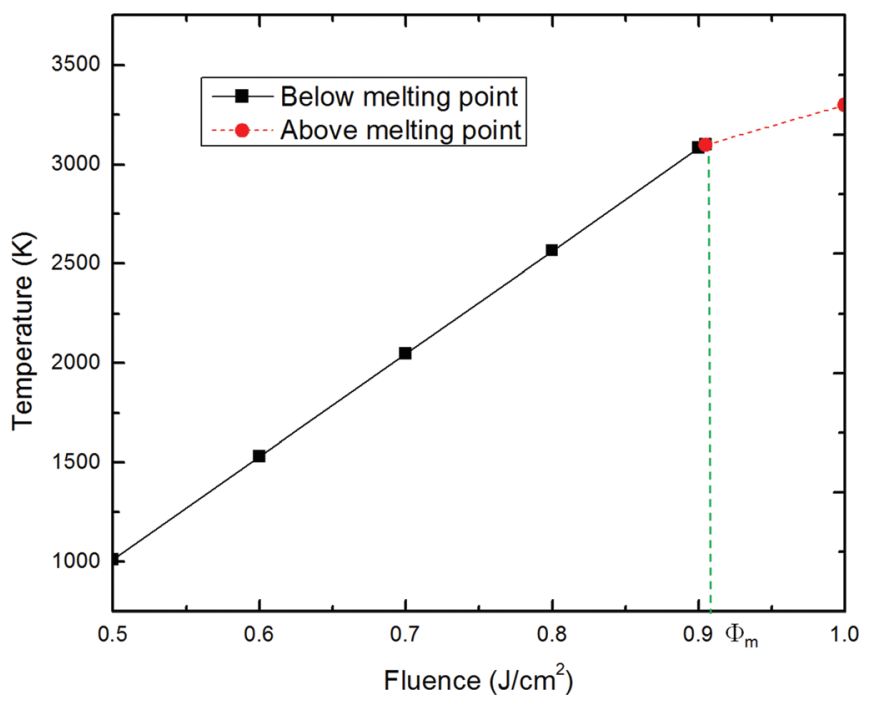

FIG. 7. Thermal simulations of peak temperatures at the end of $25 \mathrm{~ns}$ laser pulses at various fluences. The solid black line region is from the thermal simulation, and red dashed line indicates the change to liquid has occurred. more layers of graphene formed at the interface of the polycrystalline $\mathrm{SiC}$ and amorphous layer. The Raman spectra showed that the $\mathrm{SiC}$ peak was greatly reduced, and the $\mathrm{G}, \mathrm{D}$, and $2 \mathrm{D}$ peaks rose sharply signifying increased graphene layer formation. Figure 8(e) is the TEM image after 100 pulses. The total thickness affected by the laser is $\sim 75 \mathrm{~nm}$, which increased slightly compared with Figure 8(c). Interestingly, more and more $\mathrm{SiC}$ recrystallizes from the amorphous phase to polycrystalline phase, and it seems the amorphization and the recrystallization are in competition. During this process, some of the inclusions show carbon nano-structures like carbon anions in Figure 8(f). The trend of 1-100 pulse laser annealing at a fluence of $1 \mathrm{~J} / \mathrm{cm}^{2}$, which is high enough to melt the surface, is that there are increasing layers of graphene when applying more pulses, but not in a desirable fashion such as single- or multi-layer, epitaxial growth. Therefore, high fluences that cause surface melting are not the optimum conditions for epitaxial graphene growth. A lower fluence below the melting threshold was also conducted and is discussed along with environment effects and frequency effects in the next two sections.

\section{PLA environment effects}

Experiments exploring the effects of the annealing environment showed that PLA in 1 atm of $\mathrm{Ar}, \mathrm{H}_{2}$, or $\mathrm{N}_{2}$ ambient can significantly lower the graphene yield compared with PLA in vacuums as low as 1-20 mTorr. Figure 9 compares Raman spectra for PLA of c-SiC in Ar ambient and vacuum. Figure 9(a) shows results for PLA with100 pulses at $0.8 \mathrm{~J} / \mathrm{cm}^{2}$. The red (Ar) and green (vacuum) spectra have similar $\mathrm{G}$ peaks, but slightly different $\mathrm{D}$ and $2 \mathrm{D}$ peaks. The green spectrum (vacuum) has a narrower D peak and higher 2D peak, implying slightly better graphene quality. Annealing with more laser pulses, such as 500 pulses, helps differentiate the two ambient conditions as shown in Figure $9(\mathrm{~b})$ where the $\mathrm{G}, \mathrm{D}$, and $2 \mathrm{D}$ peaks rise significantly for the sample under vacuum conditions, and PLA with 500 pulses in Ar ambient is still very much the same as 100 pulses, and there is no sign of further graphitization. The existence of Ar atoms in the environment creates a pressure that could slow or suppress the free silicon atoms from leaving the surface, and therefore lowers the graphene yield. The situation is similar to the growth of graphene by thermal annealing c-SiC at high temperatures. ${ }^{21}$

\section{PLA frequency effects}

The results from Section "PLA Melting Effects" indicated that PLA at high fluences that melt the surface result in relatively poor quality graphene. In experiments to create higher quality $\mathrm{G}$, both lower fluences and pulse delivery times (frequency effects) were explored. It was found that PLA of c-SiC at fluences below $0.8 \mathrm{~J} / \mathrm{cm}^{2}$ produced no change to the $\mathrm{SiC}$ crystals and did not produce $\mathrm{G}$ regardless of frequency. But, in PLA experiments at $0.8 \mathrm{~J} / \mathrm{cm}^{2}$ in vacuum, an unusual effect between the laser repetition rate and graphene yield was discovered.

Figure 10 contrasts Raman spectra of $\mathrm{SiC}$ after pulsed laser annealing at $50 \mathrm{~Hz}$ and $1 \mathrm{~Hz}$. At $0.8 \mathrm{~J} / \mathrm{cm}^{2}$, the peak 

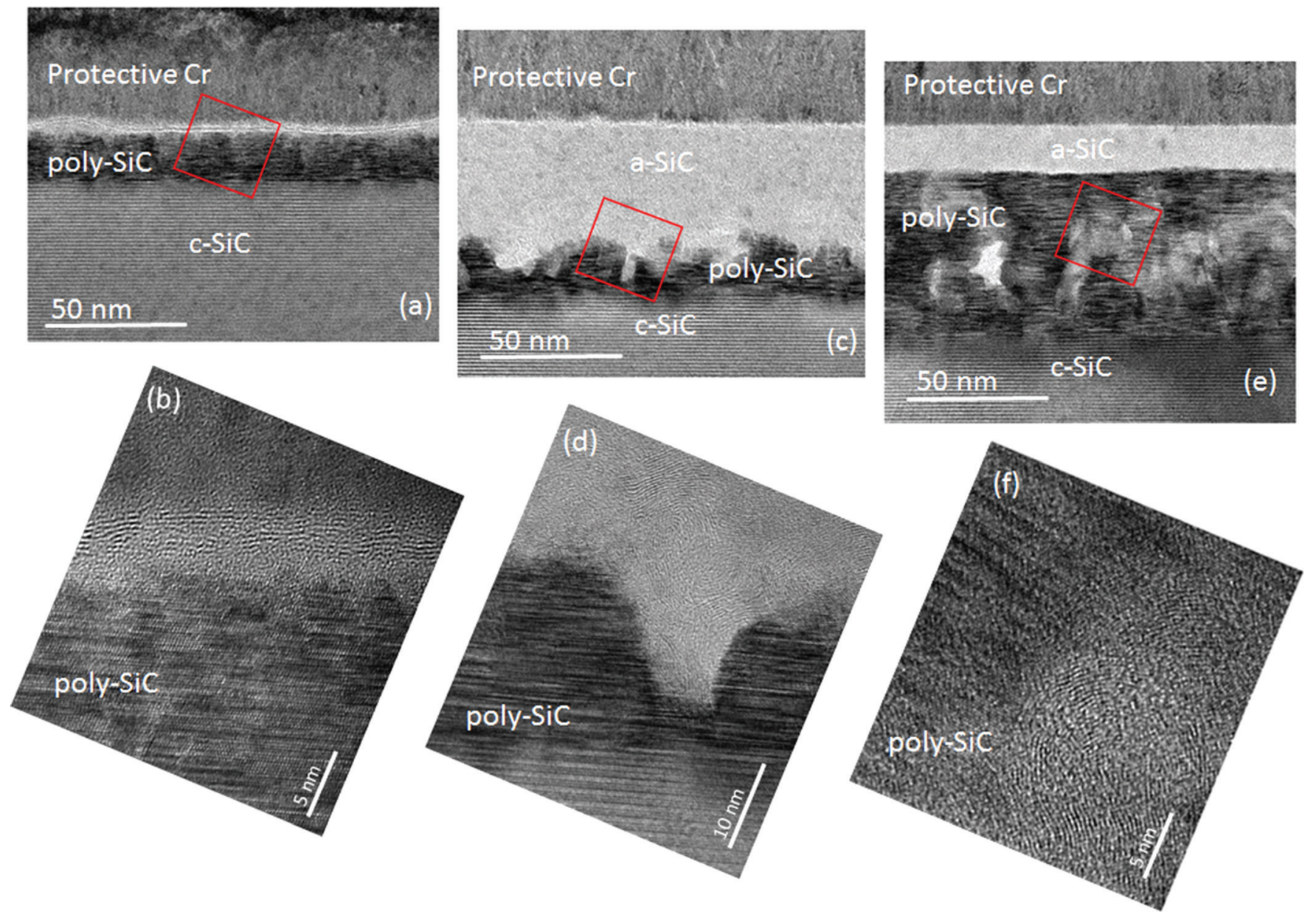

FIG. 8. TEM images comparison among pulsed laser annealing SiC with 1-100 pulses at $1 \mathrm{~J} / \mathrm{cm}^{2}$ in Ar. (a) 1 pulse. (b) Magnified image of (a). (c) 10 pulses. (d) Magnified image of (c). (e) 100 pulses. (f) Magnified image of (e).

surface temperature is $\sim 2200 \mathrm{~K}$ and is much lower than the c-SiC melting temperature of $\sim 3100 \mathrm{~K}$ according to the thermal simulation. Figure 10(a) is the Raman spectrum of PLA at $0.8 \mathrm{~J} / \mathrm{cm}^{2}$, with multiple pulses at $50 \mathrm{~Hz}$ in vacuum. With increasing number of pulses, the $\mathrm{G}$ and $2 \mathrm{D}$ peaks do not change significantly and only the D peak appears slightly, but it is still considerably smaller compared with pristine $\mathrm{SiC}$. Figure 10(b) shows the Raman spectrum of PLA SiC at $0.8 \mathrm{~J} / \mathrm{cm}^{2}$, with multiple pulses at $1 \mathrm{~Hz}$ in vacuum. The areas that were annealed with 125 pulses or more demonstrate prominent graphitic signals. So, this "frequency effect" indicates that lower repetition rate results in improved graphene growth.

To confirm the graphene growth and quality, HR-XTEM images were taken for these samples. Figure 11 compares the TEM images of PLA at $50 \mathrm{~Hz}$ (a) and $1 \mathrm{~Hz}$ (b) with 375 pulses at $0.8 \mathrm{~J} / \mathrm{cm}^{2}$. Figure 11 (a) shows little and discontinuous graphene growth, which is consistent with Raman spectra results for the same conditions. To the contrary, Figure 11(b) shows 4 layers of graphene epitaxial growth on the c$\mathrm{SiC}$ surface, and there is also a thin amorphous layer on top containing unconnected loose graphene features. When Raman spectra signal was acquired, the signal from both the epitaxial graphene and the loose graphene on top was collected. And, we believe that the defect peak, D, in Figure 10 (b) is primarily contributed from the loose graphene features in the amorphous region, and the epitaxial graphene on the c-SiC substrate has very good quality based on these TEM images.

\section{CONCLUDING REMARKS}

We have shown that ion implantation and pulsed laser annealing can be controlled to synthesize graphene and graphene nanostructures in $\mathrm{SiC}$. While we were aware that these combined techniques offered a wide range of processing parameters, some of the resulting effects were surprising. The observation that the a-SiC phase anneals/melts at lower fluence than $\mathrm{c}-\mathrm{SiC}$ is expected and occurs for other materials like Si. The enhanced graphene formation associated with the doping effect can also be rationalized. But, the exact mechanism whereby $\mathrm{SiC}$ is depleted of $\mathrm{Si}$ to allow graphene formation during rapid heating is not certain. Lee $e t$ al. ${ }^{24} \mathrm{cal}-$ culated that the amount of Si that would be lost to sublimation-even assuming melting with $500,25 \mathrm{~ns}, \mathrm{KrF}$ laser pulses - was only $\sim 10^{-2}$ atoms/ $/ \mathrm{A}^{2}$, and hypothesized a photophysical bond breaking effect. But, some of the other effects we observed such as the frequency, environment, nanostructure formation, and structural changes are not totally consistent with this interpretation.

The mechanism of the $\mathrm{Au}^{+}$"catalytic effect" for graphitization is still under investigation. $\mathrm{Au}$ and $\mathrm{Cu}$ metals have 

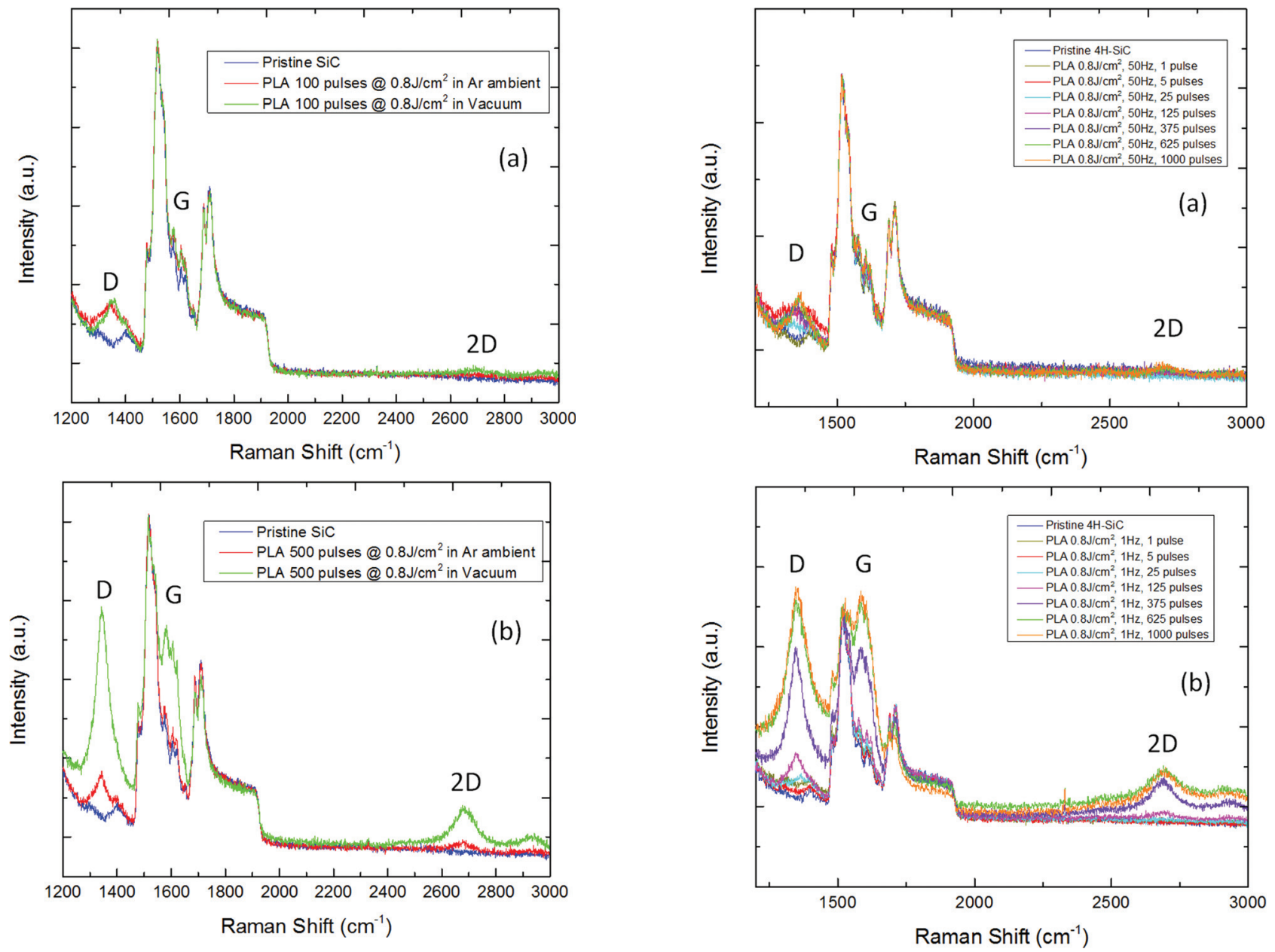

FIG. 9. Raman spectra of PLA c-SiC in Ar ambient and vacuum condition.

been used in the CVD method for graphene growth, ${ }^{20-22}$ and both exhibit a catalytic effect. The low solubility of carbon in these transition metals leads to precipitation of carbon atoms at the surface that form $\mathrm{G}$ when they cool down; this is a self-limiting process. Silicon and gold can form Au-Si eutectic alloys at a much lower melting temperature ${ }^{23}$ and may help remove $\mathrm{Si}$ atoms in a $\mathrm{Si}-\mathrm{C}$ system. However, our concentration of implanted $\mathrm{Au}$ is small, and our estimates are that it is unlikely this low concentration of Au is enough to change the absorption characteristics, and thus surface temperature, of the $\mathrm{Au}^{+}$implanted sample compared to the control sample, or to "change" the structure of the amorphous layer. The explanation we propose for graphene growth during PLA of $\mathrm{Au}^{+}$implanted $\mathrm{SiC}$ is that the laser heats the amorphous surface to a high temperature, silicon atoms start to de-bond from carbon atoms, and diffuse toward the surface where they escape. The presence of the $\mathrm{Au}$ either enhances de-bonding or loss of $\mathrm{Si}$, leaving the surface enriched with $\mathrm{C}$ atoms that bond to form graphene structures. However, it is still unverified how the Au could increase the loss rate, or how interactions between $\mathrm{Au} / \mathrm{Si}$ and $\mathrm{Au} / \mathrm{C}$ encourage graphene growth. In our study, as a result of $\mathrm{Au}^{+}$ implantation, more layers of graphene formed after laser annealing, and we confirmed that Au has a "catalytic effect." Combined with the "amorphous effect," this means that we

FIG. 10. Raman Spectrum for frequency effect. (a) Pulsed laser annealing c$\mathrm{SiC}$ in vacuum, at $0.8 \mathrm{~J} / \mathrm{cm}^{2}$, at $50 \mathrm{~Hz}$ with $1,5,25,125,375,625$, and 1000 pulses. (b) Pulsed laser annealing c-SiC in vacuum, at $0.8 \mathrm{~J} / \mathrm{cm}^{2}$, at $1 \mathrm{~Hz}$ with $1,5,25,125,375,625$, and 1000 pulses.

can better control the laser annealing process and selectively graphitize the SiC surface by II and PLA.

It is also not clear how the "frequency effect" phenomenon enhances graphene growth in PLA SiC. The temperature change during PLA increases rapidly during the $25 \mathrm{~ns}$ laser pulse, and then quickly drops back to room temperature in a few $\mu$ s, based on the thermal simulation. ${ }^{27}$ The only difference between these two conditions is the time interval between two subsequent laser pulses, which is $20 \mathrm{~ms}$ for
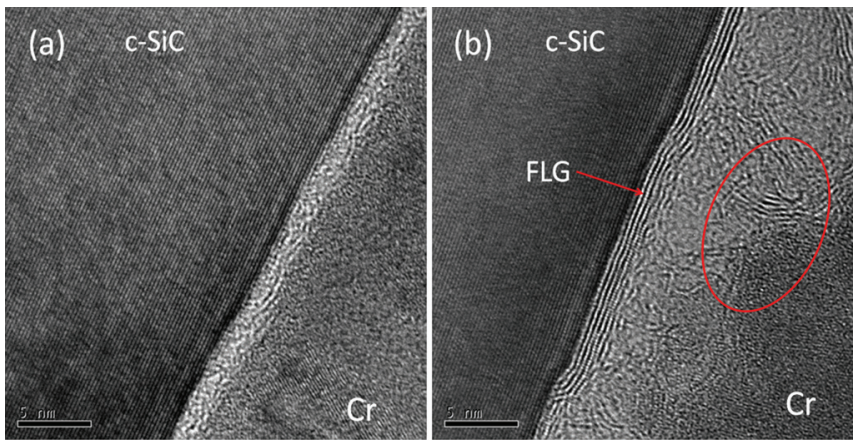

FIG. 11. HR-XTEM images (a) PLA 375 pulses at $0.8 \mathrm{~J} / \mathrm{cm}^{2}, 50 \mathrm{~Hz}$. (b) PLA 375 pulses at $0.8 \mathrm{~J} / \mathrm{cm}^{2}, 1 \mathrm{~Hz}$. 
$50 \mathrm{~Hz}$ and $1000 \mathrm{~ms}(1 \mathrm{~s})$ for $1 \mathrm{~Hz}$. Even $20 \mathrm{~ms}$ is long enough for the surface to be cooled down to room temperature compared with a few $\mu$ s, but it seems that a longer wait time at room temperature is helping the graphene growth process. In the physical process of PLA c-SiC, silicon atoms are given enough kinetic energy due to the temperature to de-bond with carbon atoms and then can desorb from the $\mathrm{SiC}$ surface. After silicon atoms leave the surface, the carbon atoms could bond with each other and form graphene. If the free silicon atoms do not leave or do not leave quickly enough, silicon atoms could inhibit the graphene growth by re-bonding with carbon atoms. In terms of time scales, the de-bonding and bonding process in the chemical reaction is in the range of a few nanoseconds to microseconds, while the surface is still hot, but the mass transportation is in the millisecond or second range when the surface is cool. It seems that the graphene growth during PLA c-SiC may not be reaction controlled but a diffusion controlled process.

We have shown that the numerous processing parameters of II and PLA can be controlled and manipulated to produce the amount and quality of G, FLG, and carbon nanostructures on $\mathrm{SiC}$. And, both are compatible with current device manufacturing methods, so they can have significant advantages for growing and patterning $\mathrm{G}$ on $\mathrm{SiC}$.

\section{ACKNOWLEDGMENTS}

We gratefully acknowledge the excellent technical support and facilities of the Nanoscale Research Facility at UF and the ion accelerator facilities at ANU. This work was partially supported by the National Science Foundation under Grant No. DMR-1305783 (AFH) and partially funded by the UF Office of Research.

${ }^{1}$ S. Tongay, M. Lemaitre, J. Fridmann, A. Hebard, B. Gila, and B. Appleton, Appl. Phys. Lett. 100, 073501 (2012).

${ }^{2}$ M. G. Lemaitre, S. Tongay, X. Wang, D. K. Venkatachalam, J. Fridmann, B. P. Gila, A. F. Hebard, F. Ren, R. G. Elliman, and B. R. Appleton, Appl. Phys. Lett. 100, 193105 (2012).
${ }^{3}$ B. R. Appleton, S. Tongay, M. Lemaitre, B. Gila, J. Fridmann, P. Mazarov, J. E. Sanabia, S. Bauerdick, L. Bruchhaus, R. Mimura, and R. Jede, Nucl. Instrum. Methods Phys. Res., Sect. B 272, 153-157 (2012).

${ }^{4}$ L. A. Giannuzzi, J. L. Drown, S. R. Brown, R. B. Irwin, and F. Stevie, Microsc. Res. Tech. 41, 285 (1998).

${ }^{5}$ L. A. Giannuzzi and F. A. Stevie, Micron 30, 197 (1999).

${ }^{6}$ J. Mayer, L. A. Giannuzzi, T. Kamino, and J. Michael, MRS Bull. 32, 400 (2007).

${ }^{7}$ M. Sugiyama and G. Sigesato, J. Electron Microsc. 53, 527 (2004).

${ }^{8}$ B. W. Kempshall, L. A. Giannuzzi, B. I. Prenitzer, F. A. Stevie, and S. X. Da, J. Vac. Sci. Technol., B 20, 286 (2002).

${ }^{9}$ M. V. Rao, P. Griffiths, O. W. Holland, G. Kelner, J. A. Freitas, D. S. Simmons, P. H. Chi, and M. Ghezzos, J. Appl. Phys. 77, 2479 (1995).

${ }^{10}$ P. Baeri, C. Spinella, and R. Reitano, Int. J. Thermophys. 20, 1211 (1999).

${ }^{11}$ C. Dutto, E. Fogarassy, and D. Mathiot, Appl. Surf. Sci. 184, 362-366 (2001).

${ }^{12}$ A. Hedler, S. Urban, F. Falk, H. Hobert, and W. Wesch, Appl. Surf. Sci. 205, $240(2003)$

${ }^{13}$ J. F. Ziegler, M. D. Ziegler, and J. P. Biersack, Nucl. Instrum. Methods Phys. Res., Sect. B 268, 1818 (2010).

${ }^{14}$ T. S. Kang, C. F. Lo, X. T. Wang, L. Liu, R. Finch, E. Douglas, S. J. Pearton, S. T. Hung, C.-J. Chang, and F. Ren, J. Vac. Sci. Technol., B 29, 041202 (2011).

${ }^{15}$ R. Saito, M. Hofmann, G. Dresselhaus, A. Jorio, and M. S. Dresselhaus, Adv. Phys. 60, 413-550 (2011).

${ }^{16}$ S. Iijima, J. Cryst. Growth 50, 675-683 (1980).

${ }^{17}$ D. Ugarte, Chem. Phys. Lett. 207, 473-479 (1993).

${ }^{18}$ N. Sano, H. Wang, I. Alexandrou, M. Chhowalla, K. Teo, G. Amaratunga, and K. Iimura, J. Appl. Phys. 92, 2783-2788 (2002).

${ }^{19}$ T. Cabioc'h, J. Riviere, and J. Delafond, J. Mater. Sci. 30, 4787-4792 (1995).

${ }^{20}$ X. Chen, L. Zhang, and S. Chen, Synth. Met. 210, 95-108 (2015).

${ }^{21} \mathrm{C}$. Berger et al., "Ultrathin epitaxial graphite: 2D electron gas properties and a route toward graphene-based nanoelectronics," J. Phys. Chem. B 108, 19912-19916 (2004).

${ }^{22}$ T. Oznuluer, E. Pince, E. O. Polat, O. Balci, O. Salihoglu, and C. Kocabas, Appl. Phys. Lett. 98, 183101 (2011).

${ }^{23}$ A. L. Pinardi and S. J. Leake, Phys. Rev. B 79, 045416 (2009).

${ }^{24}$ S. Lee, M. F. Toney, W. Ko, J. C. Randel, H. J. Jung, K. Munakata, J. Lu, T. H. Geballe, M. R. Beasley, R. Sinclair, H. C. Manoharan, and A. Salleo, ACS Nano 4, 7524 (2010).

${ }^{25}$ H. J. Hwang, C. Cho, S. K. Lim, S. Y. Lee, C. G. Kang, H. Hwang, and B. H. Lee, Appl. Phys. Lett. 99, 082111 (2011).

${ }^{26}$ M. Hattori, H. Ikenoue, D. Nakamura, K. Furukawa, M. Takamura, H. Hibino, and T. Okada, Appl. Phys. Lett. 108, 093107 (2016).

${ }^{27}$ Z. Tian, N. R. Quick, and A. Kar, Acta Mater. 54, 4273-4283 (2006). 